\title{
Max Askanazy †
}

Am 23. Oktober vefstarb in Genf der Pathologe Prof. Max Askanazy, der nicht nur als Mitarbeiter dieser Zeit-schrift, sondern aueh als Forscher, der die pathologische Ana-tomie der Verdauungsorgane wesentlich gefördert hat, ver-diemt, daß seiner an dieser Stelle gedacht werde.

Askanazy wurde am 24. Februar 1865 in Ostpreußen ge-boren, kam schon als Schüler nach Königsberg und blieb dort bis 1905. Er wurde Assistent des Pathologen Ernst Neumann, der die blutbildende Funktion des Knochenmarks entdeckt hat. Schon in Königsberg veröffeintlichte er wichtige Arbeiten, vor allem machte er die grundsätzlich wichtige Beobachtung des primären, durch Distoma verursachten Gallengangkrebses. I'm Jahre 1905 wurde er als Ordinarius der pathologisehen Anatomie nach Genf berufen, und hier erwarb er sich ein solches Ansehen, daß ihn die Stadt Genf an seinem 70. Ge-burtstag zum Ehrenbürger ernannte. Er hat zahlreiche wichtige Arbeiten veröffentlicht und durch seine Schüler ver-öffentlichen lassen und auf verschiedenen Gebieten Hervor-ragendes geleistet, besonders über Knochenmark und Blut, über tierische Parasiten, über Teratome, über Knochenpa-thologie, innere Sekretion, Kalkmetastasen und maligne Tu-moren. Besonders die Ätiologie des Krèbses hat ihn inte-ressiert, und er kam zur Formulierung, daß vier Faktoren für die Krebsentstehung maßgebend seien, eine endogene allgemeine Krebsdisposition, eine endogene Organdisposition, eine exogene Steigerung der Krebsdisposition und eine exogene lokal auslösende Ursache. Auf dem Gebiete der Verdauungskrankheiten sind seine Carcinomarbeiten von Bedeutung, außerdem hat er aber auch über Parasiten der Verdauungsorgane, über das Ulcus, über Lebercirrhose usw. wichtige Untersuchungen veröffentlicht.

Askanazy erkannte von jeher die Wichtigkeit internatio-naler Zusammenarbeit in der Wissenschaft. Nach dem Welt-krieg, unter dem er als Deutscher in einer durchaus nicht deutschfreundlichen Umgebung schwer litt, suchte er die internationale Zusammenarbeit auf einem Gebiete anzubahnen,

Max Askanazy $\dagger$.

307

für das eine solche besonders wiehtig ist und das ihm $\mathrm{re}^{1 / 8 \mathrm{f}}$ für eine intensive Bearbeitung schien, nämlich der geographi-schen Pathologie. Dureh seine Initiative kam 1928 die Grün-dung der internationalen Gesellschaft für geographische Pathologic zustande, deren Generalsekretär er wurde und die seither drei Konferenzen abgehalten hat. 1931 wurde in Genf die Lebercirrhose behandelt, 1934 in Utrecht die Arterioskle-rose, 1937 in Stockholm die Anaemien. Die nächste Konferenz sollte in Rom abgehalten werden und das Ulcus ventriculi und duodeni zum Gegenstand haben. Der Kriegsausbruch hat ihre Abhaltung bisher verhindert.

Im Sommer 1939 legte Askanazy aus Altersrücksichten sein Amt nieder. Aber sein Schüler und Nachfolger, Prof. Rutis-hauser mußte zum Grenzbewachungsdienst der schweizeri-sch@n Armee einrücken, und Askanazy mußte die Vorlesungen noch einige Zeit weiterführen. Wer den lebhaften, liebenswür-digen, sich für alles interessierenden, geistreichen Mann im letzten Sommer noch sah, ahnte nicht, daß er so bald der Krankheit zum Opfer fallen werde, deren 
Erforschung er einen wichtigen Teil seines Lebens gewidmet hat. Er mußte sich zweimal einer Operation unterziehen, und bald nach der zweiten ist er gestorben. Unsere Zeitschrift verliert in ihm einen Mitarbeiter, der ihre Bestrebungen nach internationaler Zusammenarbeit ganz besonders gewürdigt und ihr eigene und Schülerarbeiten zur Verfügung gestellt hat.

R. Staehelin. 